\title{
Crescimento e consumo hídrico de pinhão manso sob estresse salino e doses de fósforo ${ }^{1}$
}

\section{Growth and water consumption of physic nut under salt stress and phosphorus levels}

\author{
Antonio Evami Cavalcante Sousa ${ }^{2 *}$, Hans Raj Gheyi ${ }^{3}$, Karina Guedes Correia ${ }^{4}$, Frederico Antonio Loureiro \\ Soares $^{5}$ e Reginaldo Gomes Nobre ${ }^{6}$
}

\begin{abstract}
Resumo - A salinidade do solo reduz a absorção de água pelas plantas, consequentemente, o crescimento e produção das mesmas. Objetivando avaliar o crescimento do pinhão manso em função da irrigação com água salina durante o terceiro ano de produção, foi conduzido um experimento em ambiente protegido adotando-se aleatorização em blocos e esquema fatorial 5 × 2, com cinco níveis de condutividade elétrica da água de irrigação - CEa $(0,6 ; 1,2 ; 1,8 ; 2,4$ e 3,0 dS m-1) e duas doses de $\mathrm{P}_{2} \mathrm{O}_{5}$ por ano (135 e $200 \mathrm{~g}_{\text {planta }}{ }^{-1}$ ) e quatro repetições. As plantas foram cultivadas em vaso com capacidade de $200 \mathrm{~L}$ e irrigados a cada três dias. O aumento da CEa promoveu efeito significativo a partir dos 30 dias após a poda (DAP) causando reduções nas variáveis diâmetro de caule, número de folhas e área foliar. A área foliar e o número de folhas foram mais afetados, por isso são as que melhor expressam os efeitos da salinidade da água sobre o pinhão manso. A salinidade da água de irrigação interferiu negativamente no acúmulo de matéria seca das folhas e no consumo médio de água do pinhão manso reduzindo em cerca de $60 \%$ sob o tratamento de maior $\mathrm{CEa}$ em relação à menor. A área foliar foi à única variável de crescimento influenciada pelas doses de fósforo nas três avaliações e o número de folhas foi influenciado aos 30 DAP. A cultura do pinhão manso demonstra sensibilidade aos níveis de salinidade da água acima de 1,6 dS m-1.
\end{abstract}

Palavras-chave - Jatropha curcas L. Condutividade elétrica. Índices fenológicos. Energia-fontes alternativas.

\begin{abstract}
Soil salinity reduces the absorption of water by plants, consequently their growth and production. Aiming to evaluate the growth of the physic nut as a function of irrigation with saline water during the third year of growth, an experiment was conducted in a protected environment, adopting a randomized block with a $5 \times 2$ factorial design consisting of five levels of electrical conductivity of the water used for irrigation - ECw $\left(0.6 ; 1.2 ; 1.8 ; 2.4\right.$ and $\left.3.0 \mathrm{dS} \mathrm{m}^{-1}\right)$ and two levels of $\mathrm{P}_{2} \mathrm{O}_{5}$ per year (135 and $200 \mathrm{~g}$ per plant) and four replications. Plants were cultivated in pots of $200 \mathrm{~L}$ and irrigated at intervals of three days. The increase of ECW, starting from the 30th day after pruning (DAP), caused significant reduction in the variables: stem diameter, leaf number and leaf area. The leaf area and number were most affected and therefore are the best indicators to express the effects of water salinity on the physic nut. The salinity of the irrigation water interferes negatively in dry-matter accumulation in the leaves, and the mean water consumption of the physic nut is reduced by about $60 \%$ when irrigated with water with the highest $\mathrm{ECw}$ in relation to the lowest. Leaf area was the only growth variable influenced by phosphorus levels in the three evaluations, where leaf number was influenced at 30 DAP. This physic nut crop demonstrates sensitivity at water salinity levels above $1.6 \mathrm{dS} \mathrm{m}^{-1}$.
\end{abstract}

Key words - Jatropha curcas L. Electrical conductivity. Phenological indices. Energy-Alternative sources.

\footnotetext{
*Autor para correspondência

${ }^{1}$ Recebido para publicação em 31/08/2010; aprovado em 31/01/2011

Trabalho submetido e selecionado no primeiro Simpósio Brasileiro de Salinidade realizado de 12-15/10/2010 em Fortaleza, Ceará, Brasil; Parte da Tese do Doutorado do primeiro autor

${ }^{2}$ Programa de Pós-Graduação em Engenharia Agrícola, Bolsista CNPq, CTRN/UFCG, Av. Aprígio Veloso, 882, Campus Universitário, Campina

Grande-PB, Brasil, Caixa Postal 10.078, 58.109-970, evami@ibest.com.br

${ }^{3}$ Professor Visitante Nacional Sênior NEAS/UFRB, Cruz das Almas-BA, Brasil, hans@pq.cnpq.br

${ }^{4}$ Departamento de Energia Nuclear, CTG/UFPE, Bolsista DTI/CNPq, Recife-PE, Brasil, correiakg@gmail.com

${ }^{5}$ Instituto Federal de Educação Goiano, Campus Rio Verde-GO, Brasil, fredalsoares@hotmail.com

${ }^{6}$ Unidade Acadêmica de Ciências Agrárias, CCTA/UFCG, Pombal-PB, Brasil, rgomesnobre@yahoo.com.br
} 


\section{Introdução}

A região semiárida do Brasil é caracterizada por apresentar insuficiência hídrica e chuvas mal distribuídas. Uma das alternativas para aumento da produtividade das culturas nessa região é a irrigação, porém, a maior parte das águas utilizadas na irrigação contém teores relativamente moderados de sais, sendo frequentemente encontrados valores que chegam a 5,0 dS m $\mathrm{m}^{-1}$ (CAVALCANTI et al., 2005b; GHEYI et al., 1991).

Altas concentrações de sais no solo, além de reduzir o potencial hídrico do solo, podem provocar efeitos tóxicos nas plantas, causando distúrbios funcionais e injúrias no metabolismo (SILVA et al., 2003). Os sais são transportados pelas águas de irrigação e depositados no solo, onde se acumulam à medida que a água se evapora ou é consumida pelas culturas. Os sais no solo e na água reduzem a disponibilidade da água para as plantas, a tal ponto que afetam os rendimentos das culturas.

A redução no potencial hídrico dos tecidos causada pelo excesso de sais provoca restrição no crescimento uma vez que as taxas de elongação e de divisão celular dependem diretamente do processo de extensibilidade da parede celular, dessa forma, o ajustamento osmótico é essencial para o crescimento dos vegetais em meio salino e qualquer falha neste ajustamento resultará em injúrias semelhantes aos da seca, como a perda de turgescência e a redução no crescimento, resultando em plantas atrofiadas, desidratadas e consequentemente levando à morte das células (ASHRAF; HARRIS, 2004).

A utilização de espécies tolerantes à salinidade e a adoção de práticas de manejo de cultivo, do solo e da água tem propiciado o uso de águas salinas na irrigação de culturas (RHOADES et al., 2000). Entretanto, as culturas não respondem de forma semelhante à salinidade e algumas conseguem produzir rendimentos economicamente viáveis em níveis elevados de salinidade do solo (AYERS; WESTCOT, 1999; CORREIA et al., 2009).

O pinhão manso (Jatropha curcas L.) é uma espécie oleaginosa, de fácil propagação, exigente em insolação, resistente a seca e que apresenta relevante importância social e econômica para o Brasil, especialmente como fonte de biocombustível (SILVA E. N. et al., 2009). Sua utilização como matéria prima para a produção de bioenergia está embasada nas características agronômicas inerentes a espécie, tais como, alto potencial de produção de óleo, espécie de uso não alimentar e a perenidade da cultura. Estas características tornam a oleaginosa uma alternativa de complemento de renda para a agricultura familiar (ARRUDA et al., 2004; MARTINS et al., 2010).

Embora seja uma espécie adaptada à semiaridez, exigente em calor e luminosidade, a garantia de produção deverá ser maior com irrigação e para se obter um bom desenvolvimento e alta produtividade a planta exige solos férteis, com boas condições físicas e hídricas (LAVIOLA; DIAS, 2008; NERY et al., 2009).

Plantas oleaginosas são exigentes em fertilidade, apresentando drástica redução no crescimento quando submetido a condições adversas. Entre as principais técnicas aplicadas para aumentar a produtividade e a rentabilidade, destaca-se o suprimento nutricional, especialmente com o fósforo (ALMEIDA JÚNIOR et al., 2009). O fósforo é elemento essencial ao crescimento, desenvolvimento e reprodução das plantas com importante papel no processo de formação de sementes (BENNETT, 1994; LÓPEZ-BUCIO et al., 2002).

Desta forma objetivo-se neste trabalho avaliar o crescimento, acúmulo de matéria seca e consumo de água na cultura do pinhão manso sob condições de estresse salino e duas doses de fósforo durante o terceiro ano de produção.

\section{Material e métodos}

O estudo foi realizado em ambiente protegido pertencente à Unidade Acadêmica de Engenharia Agrícola da Universidade Federal de Campina Grande-PB com as seguintes coordenadas geográficas: $07^{\circ} 15^{\prime} 18^{\prime}$ ' latitude Sul, 35'52'28' de longitude Oeste e altitude média de $550 \mathrm{~m}$, o clima da região conforme a classificação climática de Köppen é do tipo Csa, que representa clima mesotérmico, sub úmido, com período de estiagem quente e seco (4 a 5 meses) e período chuvoso de outono a inverno (COELHO; SONCIN, 1982).

Adotou-se o delineamento experimental em blocos casualizados. Os tratamentos resultaram da combinação de dois fatores: salinidade da água de irrigação (CEa) com cinco níveis; 0,$6 ; 1,2 ; 1,8 ; 2,4$ e $3,0 \mathrm{dS} \mathrm{m}^{-1}$ a $25^{\circ} \mathrm{C}$ e duas doses de $\mathrm{P}_{2} \mathrm{O}_{5}$ por ano (135 e $\left.200 \mathrm{~g} \mathrm{planta}^{-1}\right)$, onde o primeiro nível de condutividade elétrica e dose de adubação são os tratamentos controle. As águas de irrigação foram preparadas a partir da adição à água de abastecimento dos sais $\mathrm{NaCl}, \mathrm{CaCl}_{2} \cdot 2 \mathrm{H}_{2} \mathrm{O}$ e $\mathrm{MgCl}_{2} .6 \mathrm{H}_{2} \mathrm{O}$ mantendo proporção equivalente $7: 2: 1$, entre os cátions $\mathrm{Na}^{+}: \mathrm{Ca}^{++}$: $\mathrm{Mg}^{++}$, respectivamente, em esquema fatorial 5 × 2 com quatro repetições.

O experimento foi implantado em abril de 2007 em espaçamento de 1,6 x 1,7 m. Foram utilizados recipientes plásticos com capacidade de $200 \mathrm{~L}$ e uma planta por vaso. O material de solo utilizado foi classificado como Argissolo Acinzentado Eutrófico (SANTOS et al., 2006), textura franco-arenoso, não salino e não sódico retirado a uma camada de $0-30 \mathrm{~cm}$ 
proveniente do distrito de São José da Mata, Campina Grande-PB.

Nos dois primeiros anos do experimento foram seguidas as recomendações de adubação sugeridas por Novais et al. (1991) para ensaios conduzidos em ambientes protegidos. O solo foi adubado na fundação com 100; 300 e $150 \mathrm{mg} \mathrm{kg}^{-1}$ de solo de $\mathrm{N}, \mathrm{P}_{2} \mathrm{O}_{5}$ e $\mathrm{K}_{2} \mathrm{O}$, respectivamente, utilizando como fonte de nutrientes uréia, superfosfato simples e cloreto de potássio, concomitantemente e para o segundo ano seguiu-se a mesma recomendação para adubação de cobertura.

No início do terceiro ano foi realizada uma poda drástica, deixando todas as plantas com altura de 60 $\mathrm{cm}$, posteriormente aplicaram-se ao solo $1 \mathrm{~kg}$ de húmus de minhoca em única dose com o objetivo de elevar o conteúdo de matéria orgânica. Na adubação mineral foi incorporado 80 g planta $^{-1}$ de N, 62 g planta $^{-1}$ de $\mathrm{K}_{2} \mathrm{O}$ e as duas doses de $\mathrm{P}_{2} \mathrm{O}_{5}\left(135\right.$ e $\left.200 \mathrm{~g}_{\text {planta }}{ }^{-1}\right)$, conforme os tratamentos, sendo estes valores fracionados igualmente $\mathrm{e}$ aplicada mensalmente durante 12 meses.

As irrigações foram realizadas ao final da tarde seguindo turno de rega de três dias e fixada uma fração de lixiviação de 0,15 ; como manejo para evitar maiores concentrações de sais no solo. Durante a condução do experimento foram realizados os seguintes tratos culturais: eliminação manual das plantas daninhas, escarificação superficial do solo a cada intervalo de duas irrigações e pulverizações realizadas uma vez por semana visando o controle preventivo de insetos e doenças fungicas.

Avaliou-se o crescimento do pinhão manso aos 30; 60 e 90 dias após a poda (DAP), através da determinação de altura de planta, diâmetro de caule, número de folhas, área foliar e ao final do ciclo (terceiro ano) foi aferido à matéria seca das folhas e consumo de água. A altura de planta foi definida considerando-se o galho principal e mensurando-se do colo da planta ao ápice, o diâmetro de caule foi medido a $5 \mathrm{~cm}$ da superfície do solo e na contagem de número de folhas consideraram-se todas as folhas totalmente expandidas e com comprimento igual ou superior a $3 \mathrm{~cm}$. A área foliar foi estimada com base em uma amostra de no mínimo $25 \%$ do número de folhas da planta utilizando-se a Equação 1, proposta por Severino et al. (2007).

$\mathrm{AF}=\sum 0,89 p^{2}$

em que,

- AF - área foliar $\left(\mathrm{m}^{2}\right)$;

- $\sum$ - somatório da área foliar;

- $p$ - comprimento da nervura central da folha (m).

A matéria seca foliar foi obtida a partir da coleta de todas as folhas de cada planta e sendo este material colocado em estufa para secar a uma temperatura de $60{ }^{\circ} \mathrm{C}$ por 72 horas. Após secagem todo o material foi pesado em balança analítica e assim determinado sua massa seca foliar total. O consumo de água das plantas de pinhão manso foi obtido através do método do balanço hídrico (diferença entre volume aplicado e volume drenado) no período de 180 DAP.

Os dados obtidos foram avaliados mediante análise de variância pelo teste $\mathrm{F}$ e nos casos de significância, realizou-se análise de regressão polinomial linear e quadrática utilizando software estatístico SISVAR-ESAL (FERREIRA, 2003).

\section{Resultados e discussão}

Observa-se na Tabela 1, a ocorrência de efeito significativo da condutividade elétrica da água de irrigação para as variáveis, altura de planta (90 DAP) e diâmetro de caule (30; 60 e 90 DAP) de pinhão manso. O estudo de regressão para altura de planta apresentou efeito quadrático aos 90 DAP, sendo o menor valor $124,09 \mathrm{~cm}$ obtido no tratamento com condutividade elétrica da água de irrigação (CEa) de 3,0 dS m $\mathrm{m}^{-1}$.

Aos 90 DAP observou-se um aumento de altura de planta de 1,74 e $0,92 \%$ nos níveis de 1,2 e $1,8 \mathrm{dS} \mathrm{m}^{-1}$, respectivamente em relação ao nível de $0,6 \mathrm{dS} \mathrm{m}^{-1}$. Contudo, no nível 3,0 dS m${ }^{-1}$, esta variável decresceu $10,14 \%$ em relação ao nível 0,6 dS m-1 (FIG. 1).

Cavalcanti et al. (2005b) observaram, em estudo sobre o comportamento da mamona irrigada com águas de condutividade elétrica variando entre 0,7 e $4,7 \mathrm{dS} \mathrm{m}^{-}$ ${ }^{1}$, uma redução de $5,85 \%$ por aumento unitário da $\mathrm{CEa}$ na altura da planta para a cultivar BRS Nordestina. É comum haver diferenças dos efeitos salinos nas espécies vegetais, entre genótipos de uma mesma espécie e estádios de desenvolvimento de um mesmo genótipo (TAIZ; ZEIGER, 2004). Para Ayers e Westcot (1999), a redução do potencial osmótico do substrato atua de forma negativa sobre os processos fisiológicos, reduzindo a absorção de água pelas raízes, inibindo a atividade meristemática e o alongamento celular, advindo, como consequência, a redução no crescimento das culturas.

Verifica-se com base nos resultados da análise de variância (TAB. 1), não haver efeito significativo das doses de fósforo (DP) e nem da interação (NS x DP) sobre a variável altura de planta nos três períodos em avaliação. Denota-se que possivelmente este fato tenha ocorrido devido à maior exigência na fase inicial de crescimento após a poda e a pouca mobilidade do fósforo no solo. No entanto, Costa et al. (2009) encontraram diferença significativa entre as doses de fósforo $(0 ; 50 ; 100 ; 150$ e 
Tabela 1 - Resumo da análise de variância para altura de planta (AP) e diâmetro de caule (DC) aos 30; 60 e 90 dias após poda (DAP) no terceiro ano em pinhão manso sob condições de estresse salino e doses de fósforo

\begin{tabular}{|c|c|c|c|c|c|c|c|}
\hline \multirow{3}{*}{ Fonte de Variação } & \multirow{3}{*}{ GL } & \multicolumn{6}{|c|}{ Quadrado Médio } \\
\hline & & \multicolumn{3}{|c|}{ 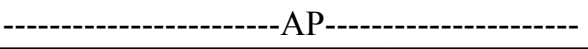 } & \multicolumn{3}{|c|}{ 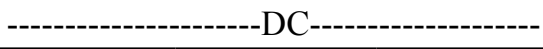 } \\
\hline & & 30 DAP & 60 DAP & 90 DAP & 30 DAP & 60 DAP & 90 DAP \\
\hline Nível Salino (NS) & 4 & $14,91^{\mathrm{ns}}$ & $123,41^{\mathrm{ns}}$ & $398,48 * *$ & $87,42 * *$ & $109,15^{* *}$ & $164,30 * *$ \\
\hline Reg. Linear & 1 & $19,60^{\mathrm{ns}}$ & $22,05^{\mathrm{ns}}$ & $884,45^{* *}$ & $326,43 * *$ & $409,51 * *$ & $560,21 * *$ \\
\hline Reg. Quadrático & 1 & $0,41^{\mathrm{ns}}$ & $378,89^{\text {ns }}$ & $531,57 * *$ & $21,09^{\mathrm{ns}}$ & $0,28^{\mathrm{ns}}$ & $88,04 * *$ \\
\hline Desvio Regressão & 2 & $19,81^{\mathrm{ns}}$ & $46,35^{\text {ns }}$ & $88,93^{\text {ns }}$ & $1,09^{\text {ns }}$ & $13,40^{\text {ns }}$ & $4,48^{\text {ns }}$ \\
\hline Dose de fósforo (DP) & 1 & $165,24^{\mathrm{ns}}$ & $52,90^{\text {ns }}$ & $129,60^{\text {ns }}$ & $49,50^{\mathrm{ns}}$ & $2,86^{\mathrm{ns}}$ & $2,86^{\mathrm{ns}}$ \\
\hline Interação (NS x DP) & 4 & $5,94^{\mathrm{ns}}$ & $25,09^{\text {ns }}$ & $9,73^{\mathrm{ns}}$ & $16,23^{\text {ns }}$ & $10,73^{\text {ns }}$ & $10,56^{\mathrm{ns}}$ \\
\hline Bloco & 3 & $36,00^{\text {ns }}$ & $77,90^{\text {ns }}$ & $67,13^{\text {ns }}$ & $8,85^{\text {ns }}$ & $16,90^{\text {ns }}$ & $51,64^{\text {ns }}$ \\
\hline Resíduo & 27 & 43,05 & 111,83 & 66,54 & 24,75 & 17,42 & 15,73 \\
\hline CV $(\%)$ & & 8,43 & 9,57 & 6,01 & 6,70 & 5,47 & 5,21 \\
\hline
\end{tabular}

** significativo $(\mathrm{p}<0,01)$, * significativo $(\mathrm{p}<0,05)$ e ns - não significativo $(\mathrm{p}>0,05)$ pelo teste $\mathrm{F}$

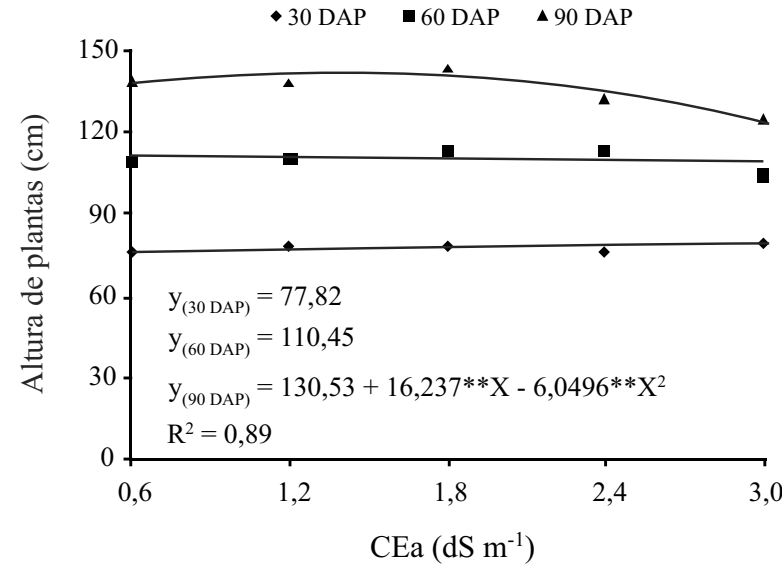

Figura 1 - Altura média de planta (AP) de pinhão manso sob condições de estresse salino aos 30; 60 e 90 dias após a poda (DAP) no terceiro ano

$200 \mathrm{~g} \mathrm{planta}^{-1}$ ) em pinhão manso a partir dos 60 dias após o transplantio. Deve-se ressaltar que o resultado obtido por Costa et al. (2009) foi no primeiro ano de cultivo e o observado neste trabalho foi no terceiro ano.

Ainda conforme dados da Tabela 1, o diâmetro de caule nas avaliações realizadas aos 30; 60 e 90 DAP, foi significativamente reduzido pela salinidade da água e os dados ajustaram-se melhor ao modelo linear (FIG. 2). Nestes períodos foram observados reduções no diâmetro do caule a partir do nível $0,6 \mathrm{dS} \mathrm{m}^{-1} \mathrm{de} 4,25 ; 4,68$ e 5,51\%, respectivamente, por aumento unitário da condutividade elétrica da água de irrigação. Utilizando a equação de regressão, observou-se que aos 30; 60 e 90 DAP, os valores para o diâmetro do caule foram de 71,11; 72,13 e $68,78 \mathrm{~mm}$, respectivamente, quando irrigados com água de maior nível de condutividade elétrica.

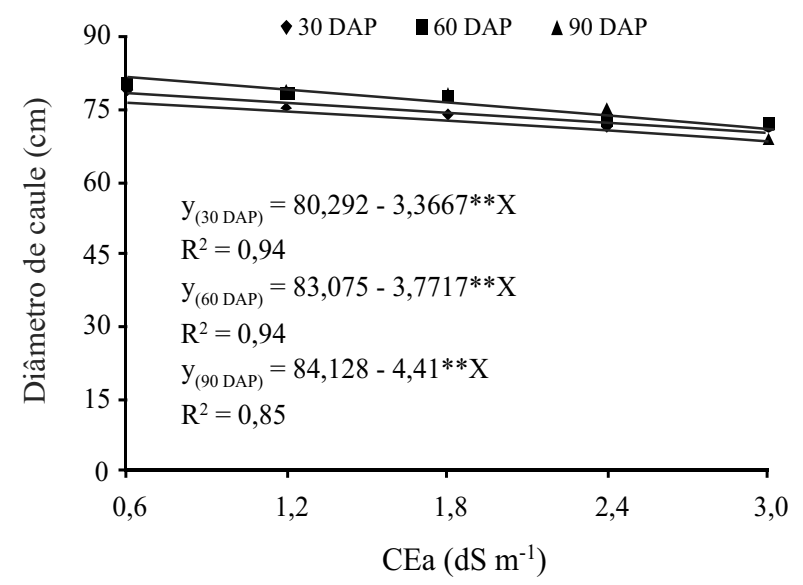

Figura 2 - Diâmetro médio de caule (DC) de plantas de pinhão manso sob condições de estresse salino aos 30; 60 e 90 dias após a poda (DAP) no terceiro ano

Este resultado concorda com Silva M. B. R. et al. (2009) que encontraram decréscimo significativo ao nível de 0,01 da probabilidade no diâmetro caulinar das plantas de pinhão manso durante o período de 144 a 312 dias após transplantio em estudo com estresse salino.

Verifica-se, ainda na Tabela 1, não haver influencia das doses de fósforo e nem da interação para 
a variável diâmetro de caule nos três períodos avaliados. Este resultado discorda com os obtidos por Martins et al. (2010), que encontraram diferença estatística estudando cinco doses de fósforo $(5,74 ; 11,48 ; 17,22$; 22,96 e 28,70 g planta $^{-1}$ ) em pinhão manso, sendo o maior diâmetro caulinar observado na dose de 22,96 $\mathrm{g} \mathrm{planta}^{-1}$.

Na Tabela 2 observa-se que o número de folhas foi significativamente influenciado pela salinidade da água de irrigação aos 60 e 90 DAP e pelas doses de fósforo aos 30 DAP.

De acordo com as equações de regressão, os menores valores de número de folhas foram $123 \mathrm{e}$ 156 folhas obtidos com 3,0 dS m${ }^{-1}$ aos 60 e 90 DAP, respectivamente. Verifica-se na Figura 3 decréscimo de 10,54 e 11,26\% para o número de folhas por aumento unitário da CEa de irrigação. Comparando os níveis de 3,0 com $0,6 \mathrm{dS} \mathrm{m}^{-1}$, verificam-se decréscimos equivalentes de 27 e $29 \%$ aos 60 e 90 DAP, respectivamente. Conforme Fageria (1989) decréscimos no número de folhas quando as plantas são cultivadas sob estresse salino, ocorrem como forma de adaptação, no sentido de minimizar as perdas de água por transpiração.

Observa-se na Tabela 2 que houve efeito significativo da dose de fósforo aos 30 DAP, em que as médias de número de folhas obtidas foram 59,2 e 53,1 para as doses de 135 e 200 g planta $^{-1}$, respectivamente. Martins et al. (2010), realizando um trabalho com mamona e pinhão manso, com finalidade de verificarem a influencia de doses de fósforo no crescimento verificaram que as adubações fosfatada não influenciaram o número de folhas.

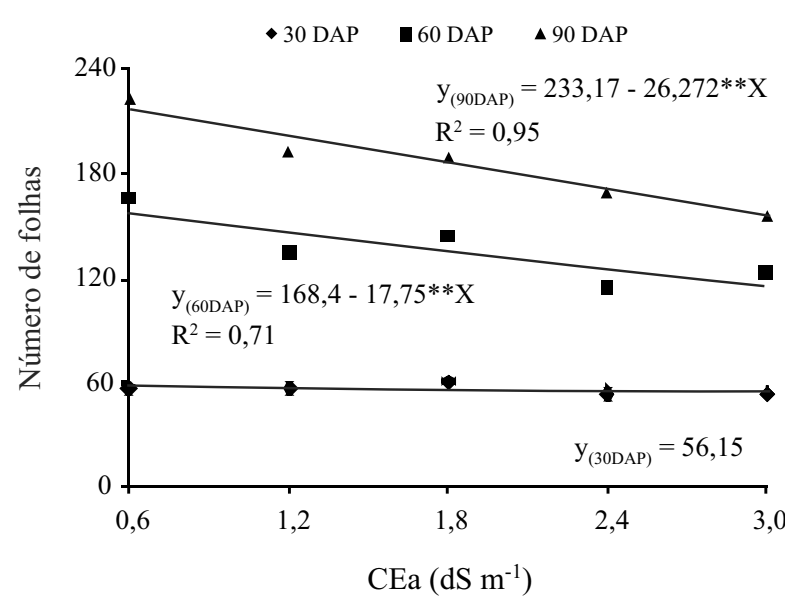

Figura 3 - Número médio de folhas (NF) em plantas de pinhão manso sob condições de estresse salino aos 30,60 e 90 dias após a poda (DAP) no terceiro ano

Conforme consta na Tabela 2, a área foliar nas três épocas de avaliação foi significativamente influenciada pela salinidade da água de irrigação (FIG. 4).

Os menores valores encontrados para a área foliar nas três épocas foram 0,$30 ; 1,50$ e 2,20 $\mathrm{m}^{2}$ quando irrigados com CEa de 3,0 $\mathrm{dS} \mathrm{m}^{-1}$. Comparando os níveis de 3,0 dS m ${ }^{-1}$ com $0,6 \mathrm{dS} \mathrm{m}^{-1}$, verificaram-se decréscimos segundo a equação de regressão de $14 ; 51,3$ e $27 \%$ aos 30; 60 e 90 DAP, respectivamente. Observa-se ainda na Figura 4 que houve um acréscimo na área foliar de $43 \%$ até a CEa $1,8 \mathrm{dS} \mathrm{m}^{-1}$ aos 30 DAP e de $11 \%$ até CEa 1,6 dS m ${ }^{-1}$ aos 90 DAP.

Tabela 2 - Resumo da análise de variância para número de folhas (NF) e área foliar (AF) aos 30; 60 e 90 dias após poda (DAP) de pinhão manso sob condições de estresse salino e doses de fósforo

\begin{tabular}{|c|c|c|c|c|c|c|c|}
\hline \multirow{3}{*}{ Fonte de Variação } & \multirow{3}{*}{ GL } & \multicolumn{6}{|c|}{ Quadrado Médio } \\
\hline & & \multicolumn{3}{|c|}{-------------------------NF------------------------ } & \multicolumn{3}{|c|}{-------------------------AF------------------------ } \\
\hline & & 30 DAP & 60 DAP & 90 DAP & 30 DAP & 60 DAP & 90 DAP \\
\hline Nível Salino (NS) & 4 & $81,34^{\mathrm{ns}}$ & $3201,48 * *$ & $5258,44 * *$ & $0,08 * *$ & $3,48 * *$ & $1,73 * *$ \\
\hline Reg. Linear & 1 & $88,20^{\mathrm{ns}}$ & $9073,80 * *$ & $19876,51 * *$ & $0,01^{\mathrm{ns}}$ & $12,00 * *$ & $3,31 * *$ \\
\hline Reg. Quadrático & 1 & $72,32^{\mathrm{ns}}$ & $902,89^{\text {ns }}$ & $192,94^{\mathrm{ns}}$ & $0,29 * *$ & $0,61 * *$ & $3,31 * *$ \\
\hline Desvio Regressão & 2 & $82,41^{\mathrm{ns}}$ & $1414,60 * *$ & $482,15^{\mathrm{ns}}$ & $0,01^{\mathrm{ns}}$ & $0,65 * *$ & $0,01^{\mathrm{ns}}$ \\
\hline Dose de fósforo (DP) & 1 & $372,10 * *$ & $176,40^{\mathrm{ns}}$ & $555,03^{\mathrm{ns}}$ & $0,61 * *$ & $2,57 * *$ & $1,97 * *$ \\
\hline Interação (NS x DP) & 4 & $8,54^{\mathrm{ns}}$ & $478,53^{\mathrm{ns}}$ & $57,46^{\text {ns }}$ & $0,05 * *$ & $1,03 * *$ & $0,84 * *$ \\
\hline Bloco & 3 & $364,57^{\mathrm{ns}}$ & $309,50^{\text {ns }}$ & $430,83^{\text {ns }}$ & $0,02 * *$ & $0,10^{\mathrm{ns}}$ & $0,13^{\text {ns }}$ \\
\hline Resíduo & 27 & 61,62 & 293,89 & 270,34 & 0,01 & 0,08 & 0,09 \\
\hline CV $(\%)$ & & 13,98 & 12,56 & 8,85 & 14,62 & 12,96 & 10,27 \\
\hline
\end{tabular}

** significativo $(\mathrm{p}<0,01)$, * significativo $(\mathrm{p}<0,05)$ e ns - não significativo $(\mathrm{p}>0,05)$ pelo teste $\mathrm{F}$ 


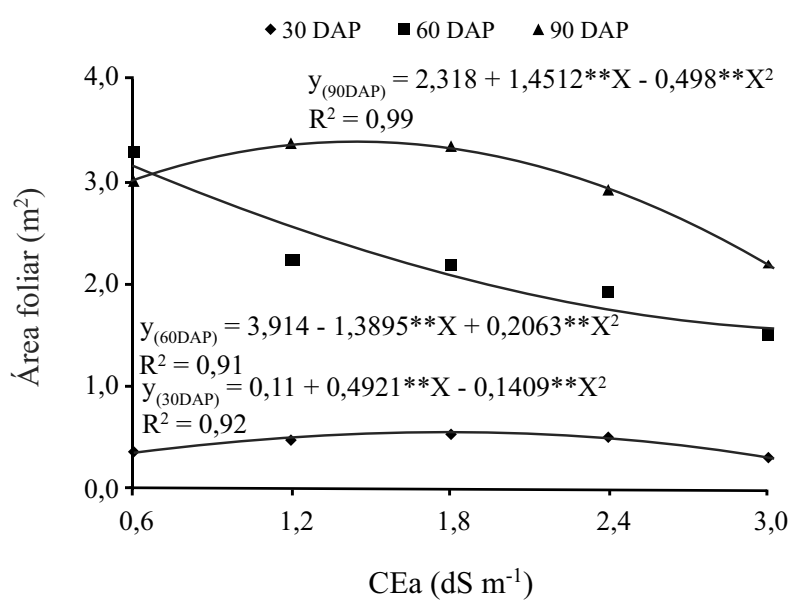

Figura 4 - Área foliar média (AF) em plantas de pinhão manso sob condições de estresse salino aos 30; 60 e 90 dias após a poda (DAP) no terceiro ano

$\mathrm{O}$ número de folhas depende da formação e desenvolvimento de primórdios foliares, enquanto a área foliar é função da expansão celular. Assim, os resultados sugerem que a expansão foliar foi mais sensível ao estresse salino nos três períodos de avaliação que o desenvolvimento dos primórdios, pois observou-se efeito significativo a partir dos 30 DAP. O estresse salino pode afetar o crescimento celular e a expansão das folhas, tanto através da redução na pressão de turgescência como na extensibilidade da parede celular (PRISCO, 1980). Cavalcanti et al. (2005a), verificaram em plantas de mamona, redução de $6,55 \%$ por aumento unitário da CEa na área foliar.

$\mathrm{Na}$ Tabela 2, observa-se efeito significativo em área foliar submetida às doses de fósforo aos $30 \mathrm{DAP}$ apresentando médias de 0,56 e $0,31 \mathrm{~m}^{2}$, aos 60 DAP 2,49 e $1,99 \mathrm{~m}^{2}$ e aos 90 DAP 28,91 e $30,35 \mathrm{~m}^{2}$ para as plantas que receberam 135 e $200 \mathrm{~g}$ de $\mathrm{P}_{2} \mathrm{O}_{5}$, respectivamente. Este resultado corrobora com Costa et al. (2009) que também obtiveram efeito isolado significativo de doses de fósforo em pinhão manso no primeiro ano de cultivo. No entanto, Souza et al. (2009) e Martins et al. (2010) estudando doses de fósforo em mamona e pinhão manso, respectivamente, não obtiveram resultados significativos isolados.

Também é observado efeito significativo sob a interação dos fatores (NS x DP) sobre o crescimento da área foliar aos 30; 60 e 90 dias após a poda (FIG. 5).

Observa-se na Figura 5 A e B, aos 30 e 60 DAP que as plantas que receberam a menor dose de fósforo foram as que mais desenvolveram-se, obtendo área foliar superior as plantas de pinhão manso que receberam $200 \mathrm{~g}$ de $\mathrm{P}_{2} \mathrm{O}_{5}$ na adubação. Aos 90 DAP (FIG. 5C) as plantas que eram irrigadas com água de 0,$6 ; 3,0 \mathrm{dS} \mathrm{m}^{-1}$ e dose de $200 \mathrm{~g}$ de fósforo obtiveram crescimento superior as plantas de pinhão manso que receberam a dose de $135 \mathrm{~g}$ de fósforo, nos demais tratamentos de nível salino a dose de $135 \mathrm{~g}$ de fósforo refletiu nas plantas de maior desenvolvimento.

Segundo a análise de variância (TAB. 3) observase que a matéria seca das folhas e o consumo de água das plantas de pinhão manso foram significativamente influenciados pela salinidade da água de irrigação, entretanto, não foram influenciadas pela doses de fósforo.
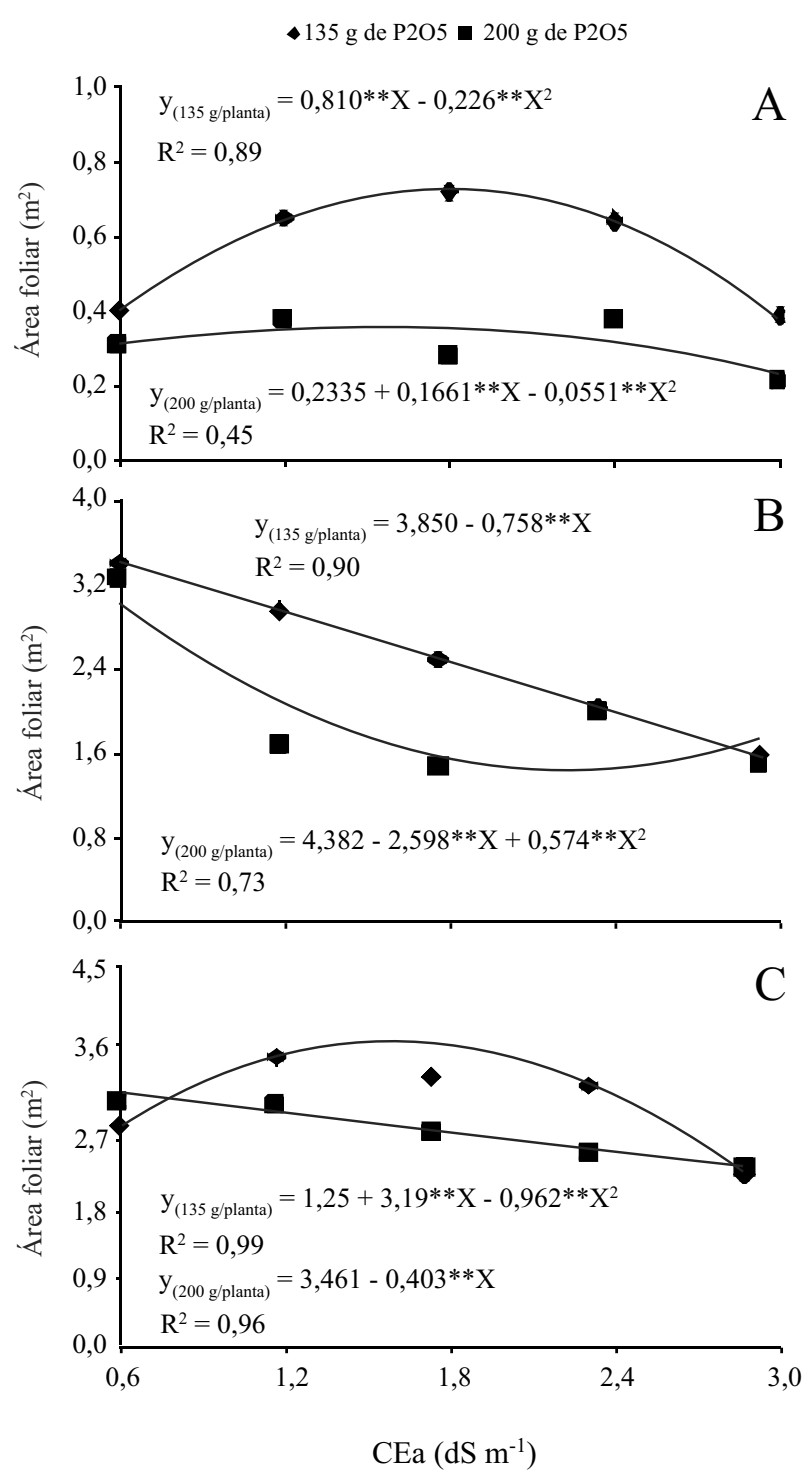

Figura 5 - Efeito de doses de fósforo em função dos diferentes níveis de salinidade da água de irrigação na área foliar média de plantas de pinhão manso no terceiro ano aos 30 (A), 60 (B) e 90 (C) dias após a poda 
Tabela 3 - Resumo da análise de variância para matéria seca das folhas (MSF) e consumo de água (CA) de pinhão manso sob condições de estresse salino e doses de fósforo aos 180 DAP

\begin{tabular}{lccc}
\hline \multirow{2}{*}{ Fonte de Variação } & GL & \multicolumn{2}{c}{ Quadrado Médio } \\
\cline { 3 - 4 } & & $24734,70^{* *}$ & CA \\
\hline Nível Salino (NS) & 4 & $24437,74^{\text {ns }}$ & $83225,90^{* *}$ \\
Reg. Linear & 1 & $11,41^{* *}$ & $328224,23^{* *}$ \\
Reg. Quadrático & 1 & $2998,99^{\text {ns }}$ & $3167,00^{* *}$ \\
Desvio Regressão & 2 & $23,13^{\text {ns }}$ & $756,19^{\text {ns }}$ \\
Dose de fósforo (DP) & 1 & $331,23^{\text {ns }}$ & $2865,91^{\text {ns }}$ \\
Interação (NS x DP) & 4 & $4965,56^{\text {ns }}$ & $1662,02^{\text {ns }}$ \\
\hline Bloco & 3 & 6004,32 & $2291,12^{* *}$ \\
Resíduo & 27 & 19,22 & 676,58 \\
CV (\%) & & 9,24 \\
\hline
\end{tabular}

** significativo $(\mathrm{p}<0,01)$, significativo $(\mathrm{p}<0,05)$ e ns - não significativo $(\mathrm{p}>0,05)$ pelo teste $\mathrm{F}$

Observa-se que o acúmulo de matéria seca das folhas segundo a equação foi crescente até o nível de salinidade de $1,6 \mathrm{dS} \mathrm{m}^{-1}$ com o acúmulo de 455,71 g que refere-se a $17 \%$ de acréscimo (FIG. 6).

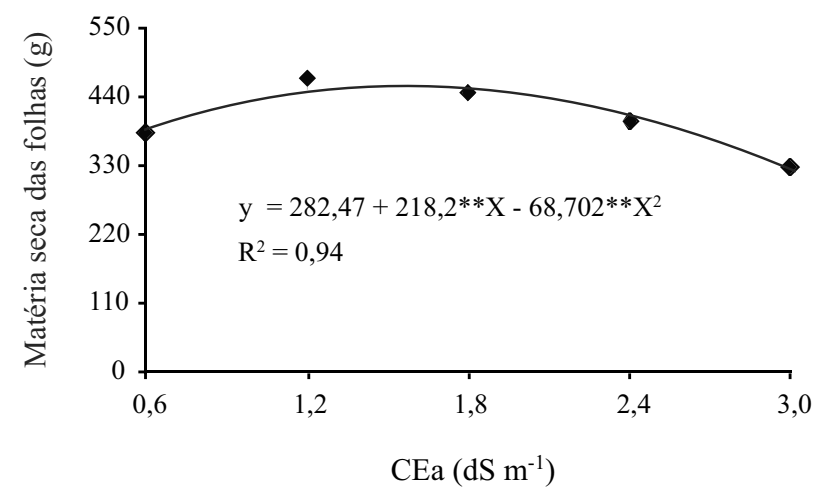

Figura 6 - Matéria seca média de folhas (MSF) das plantas de pinhão manso sob condições de estresse salino ao final do ciclo (180 DAP)

A partir da condutividade elétrica de $1,6 \mathrm{dS} \mathrm{m} \mathrm{m}^{-1}$ a matéria seca da folha decresceu $30 \%$ com o aumento da salinidade da água de irrigação quando comparado a CEa de 3,0 dS m ${ }^{-1}$. Verificou-se também que a diferença percentual entre o menor e o maior nível de salinidade da água de irrigação foi de aproximadamente 18\% podendo-se inferir que o aumento da salinidade da água de irrigação tem interferência direta no acúmulo de matéria seca das folhas. Silva et al. (2005) pesquisando o desenvolvimento de duas cultivares de mamona sob estresse salino obtiveram decréscimo de 9,9\% para cada aumento unitário da salinidade da água de irrigação, no entanto, o efeito foi linear.

O fósforo mesmo sendo um elemento de fundamental importância para desenvolvimento das culturas e apesar da variação das doses (135 a $200 \mathrm{~g}$ de $\mathrm{P}_{2} \mathrm{O}_{5}$ vaso $^{-1}$ ) fornecida às plantas, não foram constatadas ocorrência de efeito significativo conforme mostrado na Tabela 3 para a matéria seca das folhas e consumo de água. Entretanto, Almeida Júnior et al. (2009), estudando o efeito da adubação fosfatada $\left(0 ; 3 ; 6 ; 9 ; 13\right.$ e 15 g planta $\left.^{-1}\right)$ sobre o crescimento inicial da mamoneira verificaram resposta significativa à adubação fosfatada em todas as características avaliadas, inclusive matéria seca total, adequando-se ao modelo quadrático e o melhor resultado foi encontrado com a dose de 8 g planta $^{-1}$ de fósforo.

Conforme observa-se na Figura 7 o consumo de água durante os 180 DAP adequou-se ao modelo linear decrescente, em que segundo o modelo de regressão, o consumo de água com o aumento da salinidade da água de irrigação, apresentou redução de $22,5 \%$ por aumento unitário da condutividade elétrica da água.

O consumo médio hídrico do pinhão manso por evento de irrigação durante os 180 dias em estudo foram de 8,$01 ; 6,67 ; 5,26 ; 3,87$ e $3,23 \mathrm{~L}^{*}$ planta $^{-1}$ para 0,$6 ; 1,2 ; 1,8 ; 2,4$ e $3,0 \mathrm{dS} \mathrm{m} \mathrm{m}^{-1}$, respectivamente. Este resultado evidencia que o aumento da salinidade causa decréscimo do consumo de água pelas plantas, sendo uma das causas, a redução do potencial osmótico condicionando a um desenvolvimento inferior principalmente na área foliar. 


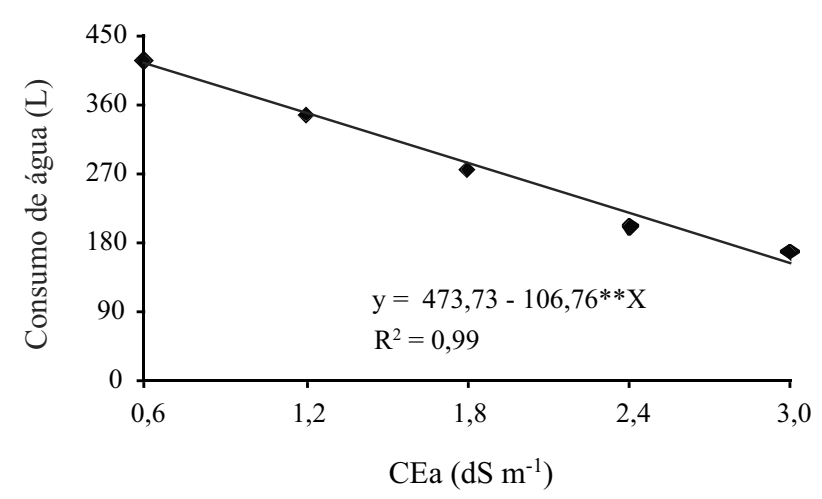

Figura 7 - Consumo médio de água de plantas de pinhão manso sob condições de estresse salino durante 180 DAP

Nery et al. (2009) pesquisando cinco níveis de salinidade da água em pinhão manso no segundo ano, verificaram em avaliações a cada 21 dias que houve decréscimo de $59,45 \%$ no consumo de água do nível 0,6 a $3,0 \mathrm{dS} \mathrm{m}^{-1}$, valor semelhante ao encontrado neste trabalho que foi de $59,49 \%$ nas mesmas condições de pesquisa.

\section{Conclusões}

1. O diâmetro de caule, número de folhas e consumo de água são afetados linear e negativamente pela salinidade da água de irrigação;

2. A área foliar foi a única variável de crescimento influenciada pelas doses de fósforo nas três avaliações e o número de folhas foi influenciado somente aos $30 \mathrm{DAP}$;

3. A salinidade da água de irrigação a partir de $1,6 \mathrm{dS} \mathrm{m}^{-1}$ interfere negativamente no acúmulo de matéria seca das folhas de pinhão manso;

4. O consumo médio de água do pinhão manso diminuiu $22,5 \%$ por aumento unitário da salinidade da água de irrigação durante 180 dias;

5. O pinhão manso demonstra sensibilidade a salinidade da água de irrigação com condutividade elétrica superior a $1,6 \mathrm{dS} \mathrm{m}^{-1}$.

\section{Agradecimentos}

Ao Conselho Nacional de Pesquisa e Desenvolvimento Cientifico e Tecnológico - CNPq, pela concessão do auxílio financeiro e bolsa, ao primeiro autor, para realização deste trabalho.

\section{Referências}

ALMEIDA JÚNIOR, A. B. et al. Efeito de doses de fósforo no desenvolvimento inicial da mamoneira. Revista Caatinga, v. 22, n. 01, p. 217-221, 2009.

ARRUDA, F. P. et al. Cultivo de pinhão manso (Jatropha curcas L.) como alternativa para o semiárido nordestino. Revista Brasileira de Oleaginosas e Fibrosas, v. 8, n. 01, p. 789-799, 2004.

ASHRAF, M.; HARRIS, P. J. C. Potential biochemical indicators of salinity tolerance in plants. Plant Science, v. 166, n. 01, p. 3-16, 2004.

AYERS, R. S.; WESTCOT, D. W. A qualidade da água na agricultura. 2 ed. Campina Grande: UFPB. 1999, 218 p.

BENNETT, W. (Ed.) Nutrients deficiencies and toxicities in crop plants. 2 ed. St. Paul: APS. 1994, 202p.

CAVALCANTI, M. L. F. et al. Índices ecofisiológicos da mamoneira sob estresse salino. Revista Brasileira de Engenharia Agrícola e Ambiental, v. 9, suplemento, p. 6670, 2005a.

CAVALCANTI, M. L. F. et al. Tolerância da mamoneira BRS 149 à salinidade: Germinação e características de crescimento. Revista Brasileira de Engenharia Agrícola e Ambiental, v. 9, suplemento, p. 57-61, 2005b.

COELHO, M. A.; SONCIN, N. B. Geografia do Brasil. São Paulo: Moderna, 1982. 368 p.

CORREIA, K. G. et al. Crescimento, produção e características de fluorescência da clorofila $a$ em amendoim sob condições de salinidade. Revista Ciência Agronômica, v. 40, n. 04, p. 514-521, 2009.

COSTA, N. V. da, et al. Crescimento de plantas de pinhão manso em resposta à adubação fosfatada: $1^{\circ}$ ano de avaliação. In: CONGRESSO BRASILEIRO DE PESQUISAS DE PINHÃO MANSO, 1, Brasília. Anais... Brasília, ABPPM, 2009.

FAGERIA, N. K. Solos tropicais e aspectos fisiológicos das culturas. Brasília: EMBRAPA, 1989. .425 p.

FERREIRA, D. F. SISVAR 4.6 Sistema de análises estatísticas. Lavras: UFLA, 2003. 32 p.

GHEYI, H. R.; MEDEIROS, J. F.; BATISTA, M. A. F. Prevenção, manejo e recuperação de solos salinos e sódicos. Mossoró: ESAM, 1991. 70 p.

LAVIOLA, B. G.; DIAS, L. A. dos S. Teor e acúmulo de nutrientes em folhas e frutos de pinhão manso. Revista Brasileira de Ciência do Solo, v. 32, n. 05, p. 1969-1975, 2008.

LÓPEZ-BUCIO, J. L. et al. Phosphate availability alters architecture and cause changes in hormone sensitivity in the Arabidopsis root system. Plant Physiology, v.129, n. 01, p.244-256, 2002.

MARTINS, L. D. et al. Desenvolvimento inicial de mamona e pinhão manso em solo submetido a diferentes corretivos e doses de fósforo. Revista Verde, v. 5, n. 01, p. 143-150, 2010. 
NERY, A. R. et al. Crescimento e desenvolvimento do pinhão manso irrigado com águas salinas sob ambiente protegido. Revista Brasileira de Engenharia Agrícola e Ambiental, v. 13, n. 05 , p. $551-558,2009$.

NOVAIS, R. F.; NEVES, J. C. L.; BARROS, N. F. Ensaios em ambiente controlado. In: OLIVEIRA, A. J. et al. (Ed.) Métodos de pesquisa em fertilidade de solo. Brasília: EMBRAPA. 1991. cap. 2, p. 189-253.

PRISCO, J. T. Alguns aspectos da fisiologia do "stress" salino. Revista Brasileira de Botânica, v. 3, p. 85-94, 1980.

RHOADES, J. D.; KANDIAH, A.; MASHAL, A. M. Uso de águas salinas para produção agrícola: Campina Grande. UFPB. 2000. 117 p.

SANTOS, H. G. et al. Sistema brasileiro de classificação de solos. 2 ed. Rio de Janeiro: Embrapa Solos, 2006. 306p.

SEVERINO, L. S.; VALE, L. S.; BELTRÃO, N. E. de M. A simple method for measurement of Jatropha curcas leaf area. Revista Brasileira de Oleaginosas e Fibrosas, v. 11, n. 01, p. 9-14, 2007.
SILVA, E. N. et al. Acúmulo de íons e crescimento de pinhão manso sob diferentes níveis de salinidade. Revista Ciência Agronômica, v. 40, n. 02, p. 240-246, 2009.

SILVA, J. V. et al. Physiological responses of $\mathrm{NaCl}$ stressed cowpea plants grown in nutrient solution supplemented with $\mathrm{CaCl}_{2}$. Brazilian Journal of Plant Physiology, v. 15, n. 02, p. $99-105,2003$.

SILVA, M. B. R. et al. Cultivo de pinhão manso sob condições de estresse hídrico e salino, em ambiente protegido. Revista de Biologia e Ciências da Terra, v. 9, n. 02, p. 74-79, 2009.

SILVA, S. M. S. et al. Germinação e crescimento inicial de duas cultivares de mamoneira sob estresse salino. Revista Brasileira de Engenharia Agrícola e Ambiental, v. 9, suplemento p. 347-352, 2005.

SOUZA, K. S. de, et al. Avaliação dos componentes de produção da mamoneira em função de doses de calcário e fósforo. Revista Caatinga, v. 22, n. 04, p.116-122, 2009.

TAIZ, L.; ZEIGER, E. Fisiologia vegetal, 2 ed. Porto Alegre: Artmed, 2004. 719 p. 